Gut, 1988, 29, 503-510

\title{
Disordered regulation of the in vitro immunoglobulin synthesis by intestinal mononuclear cells in Crohn's disease
}

\author{
H W VERSPAGET, A S PEÑA, I T WETERMAN, AND C B H W LAMERS \\ From the Department of Gastroenterology and Hepatology, University Hospital, Leiden, The Netherlands
}

SUMMARY In vitro immunoglobulin synthesis by isolated intestinal mononuclear cells of macroscopically normal mucosa from patients with Crohn's disease has been studied and results compared with those obtained with cells from normal mucosa of resection specimens from patients with colonic carcinoma, or other intestinal disorders. The total lamina propria mononuclear cells (LPMC) in Crohn's disease produced spontaneously less IgA and more IgG than the control groups, but no difference was observed for IgM. An enriched lymphocyte fraction (LPL) of the Crohn's disease patients showed a higher spontaneous synthesis of IgA and IgG when compared with controls. In contrast, another fraction enriched for macrophages (LPM) produced spontaneously less IgA, IgG, and IgM in Crohn's, than in control patients. Incubation with pokeweed mitogen (PWM) decreased immunoglobulin synthesis by LPMC in Crohn's disease and controls, and this was enhanced by simultaneous incubation with concanavalin A. In controls PWM stimulation increased immunoglobulin synthesis by LPL and decreased immunoglobulin synthesis by LPM. In Crohn's disease, however, PWM had no effect on either fraction. This study shows major differences in the regulation of the immunoglobulin synthesis by intestinal cells between Crohn's disease and controls.

The immune system appears to play a major role in the pathogenesis of Crohn's disease (CD) as seen by the increased infiltration of the intestinal mucosa by lymphocytes, plasma cells, and mononuclear phagocytes. It has been suggested that in Crohn's disease the immune response at the intestinal level towards the numerous luminal antigens functions inadequately and leads to chronic inflammation. It is further suggested that immunoglobulins play an important role in the local immunoregulation because they are directly involved in the clearance of foreign antigens. ${ }^{1-3}$

Previous studies on the immunoregulation in Crohn's disease were mainly done on peripheral blood mononuclear cells and revealed several contrasting abnormalities. For example, that Crohn's disease is accompanied by an abnormal B-cell activation, ${ }^{45}$ an enhanced spontaneous immunoglobulin synthesis ${ }^{6}$ and an increased suppressor T-cell activity for immunoglobulin $M^{8}{ }^{8}$ Studies on the immuno-

Address for correspondence: Hein W Verspaget PhD, Dept of Gastroenterology and Hepatology, Building 1, C4-P012, University Hospital, Rijnsburgerweg 10, 2333 AA Leiden, The Netherlands.

Received for publication 24 September 1987 regulation in Crohn's disease, however, should preferably be done with cells from the target organ - that is, the intestine. Bull and Bookman ${ }^{9}$ applied a technique by which through mild enzymatic dissociation lamina propria mononuclear cells (LPMC) could be isolated for in vitro studies. This technique has been used in a few studies on the regulation of the intestinal immunoglobulin synthesis and revealed a decreased spontaneous immunoglobulin production in Crohn's disease with cells refractory to mitogen stimulation ${ }^{610}$ and normal T-cell function. ${ }^{112}$

This study was undertaken to dissect the regulation of the immunoglobulin synthesis in Crohn's disease by studying LPMC and two major subpopulations of LPMC, lymphocytes (LPL) and macrophages (LPM), obtained by counterflow elutriaton centrifugation as previously published,,$^{13}$ in their response to known stimulatory (pokeweed mitogen) and suppressive (concanavalin A) signals of the immunoglobulin synthesis.

\section{Methods}

INTESTINAL MONONUCLEAR CELLS

Specimens of intestine were obtained from patients 
who underwent a surgical resection for Crohn's disease $(n=14)$, intestinal carcinoma $(n=24)$, diverticulitis $(n=7)$, incontinence $(n=1)$, ulcerative colitis $(n=1)$, and a non-Hodgkin lymphoma $(n=1)$. Crohn's disease patients were six men and eight women, mean age 40 years (19-76). Six patients received corticosteroids $(n=5)$ or azathioprine $(n=1)$ before surgery. Five had large bowel resection and nine had small bowel resection. The colon carcinoma patients consisted of 18 men and six women, mean age 68 years (27-88). Eighteen had a large bowel resection and from six small bowel tissue was obtained as a result of resection of a proximal colon tumour. The group of patients with other disorders $(n=10)$ consisted of six women and four men, mean age 61 years (43-81). Nine had a large bowel resection and one a small bowel resection. The control tissues used for intestinal cell isolation were excised at least $10 \mathrm{~cm}$ from the lesion and showed no signs of histological involvement. From the Crohn's disease patients macroscopically non-inflamed tissue was used, eight specimens showed microscopic evidence of inflammation.

The mononuclear cells from the intestine were isolated by the method of Bull and Bookman' with modifications as previously described.$^{13}$ Fresh specimens were transported in Hank's balanced salt solution (HBSS) with $125 \mu \mathrm{g}$ streptomycin, $125 \mathrm{U}$ penicillin and $6 \cdot 25 \mu \mathrm{g}$ amphotericin $\mathrm{B} / \mathrm{ml}$. Mucosa was separated from the muscularis mucosa by sharp dissection, washed in calcium and magnesium free HBSS (CMF-HBSS), cut into $5 \mathrm{~mm}^{2}$ pieces and weighed. The tissue fragments were incubated while shaking in $1 \mathrm{mM}$ dithiothreitol CMF-HBSS, at room temperature for 10-15 minutes to remove mucus and washed again with CMF-HBSS. The fragments were then reduced in size to $1-2 \mathrm{~mm}^{2}$ and freed of epithelial and crypt cells by five to six one hour incubations in $0.75 \mathrm{mM}$ EDTA-CMF-HBSS at $37^{\circ} \mathrm{C}$ with constant magnetic stirring in a Wheaton cellstir. When no more crypt cells were seen the lamina propria fragments were washed twice in RPMI 1640 tissue culture medium, supplemented with $20 \mathrm{mM}$ HEPES (Gibco), containing 5\% fetal calf serum (FCS) and antibiotics. To obtain monodispersed lamina propria cells the remaining tissue fragments were incubated in RPMI 1640 with 20 mM HEPES, $10 \%$ FCS, 2000-4000 U collagenase (CLSPA Worthington) $15.000 \mathrm{U}$ DNase and antibiotics at $37^{\circ} \mathrm{C}$ in a Wheaton cellstir during $12-15$ hours under constant magnetic stirring. The dissociated cells were harvested by eluting the medium through a nylon mesh filter in order to remove tissue remnants and clumps. The cells were washed three times in culture medium and mononuclear cells were obtained by Ficoll/Hypaque gradient density centrifugation (recovery 55\%). The interface cells were washed again three times in culture medium and used for culture experiments. Alternatively, enriched subpopulations of intestinal cells were obtained by counterflow elutriation centrifugation as described previously..$^{13}$ Elutriations were carried out with a constant flow rate of $18 \mathrm{ml} / \mathrm{min}$ at $4^{\circ} \mathrm{C}$ of RPMI 1640 medium supplemented with antibodies and newborn calf serum and DNase. Eight fractions of $90 \mathrm{ml}$ each were collected consisting of predominantly lymphocytes (LPL, fractions 0-1), macrophages (LPM, fraction 5) and plasma cells at speeds of 2700,1400 , and $0 \mathrm{rpm}$, respectively. Mean cell recovery after elutriation was $75 \%$. After washing cells were identified and used for the culture experiments.

\section{IN VITRO IMMUNOGLOBULIN SYNT.HESIS}

The intestinal mononuclear cells were cultured with or without pokeweed mitogen (PWM, 1:100 Gibco). To study the T-cell dependent suppression of the immunoglobulin synthesis, cells were also cultured in the presence of concanavalin A (ConA) at a concentration of $5 \mu \mathrm{g} / \mathrm{ml}$ in combination with PWM. The cells were cultured, in duplicate, in RPMI 1640 supplemented with $2 \mathrm{mM}$ glutamine, $10 \%$ FCS, $200 \mu \mathrm{g}$ streptomycin, $200 \mathrm{U}$ penicillin and $1.2 \mu \mathrm{g}$ amphotericin $B$, at a concentration of $1 \times 10^{6} \mathrm{cells} / \mathrm{ml}$. The cultures were set in $1 \mathrm{ml}$ volumes in 24 well culture plates (Costar) and kept at $37^{\circ} \mathrm{C}$ in an incubator with a $5 \% \mathrm{CO}_{2}-95 \%$ air gas mixture for seven days. The cultures were terminated by centrifugation of the cells and collection of the supernatants which were kept at $-20^{\circ} \mathrm{C}$ till further analysis. To be able to measure the amount of immunoglobulin present in the cells at the beginning of the cultures $1 \times 10^{6}$ starting cells in $1 \mathrm{ml}$ culture medium were lysed by sonification and the supernatants were collected after centrifugation. The human or crossreactive immunoglobulins present in the last washing medium and the culture medium were usually found to be below detection limit $(<10$ $\mathrm{ng} / \mathrm{ml})$.

MEASUREMENTS OF IgA, IgG AND IgM IN THE SUPERNATANTS OF THE CULTURES

We applied an enzyme linked immunosorbent assay (ELISA) as described previously ${ }^{14}$ for the measurements of $\operatorname{IgA}, \operatorname{IgG}$, and $\operatorname{IgM}$ in the cell culture supernatants. In brief, rabbit antihuman $\operatorname{IgA}, \operatorname{IgG}$, and IgM (1/1000-1/2500 Dako) were coated on separate polyvinylchloride microplates (Dynatech) overnight at $4^{\circ} \mathrm{C}$. After washing, the wells were filled with standards $\operatorname{IgA}, \operatorname{IgG}$, and $\operatorname{IgM}$ or optimal dilutions of culture supernatants $(1 / 1-1 / 100)$, in triplicate, and incubated for two hours at $37^{\circ} \mathrm{C}$. The plates were washed and alkaline phosphatase con- 
Table 1 Yield, viability and percentage distribution of subpopulations of intestinal cells obtained by EDTACollagenase-DNase dissociation of mucosa from resected intestine of patients with Crohn's disease, colon carcinoma, and other disorders

\begin{tabular}{|c|c|c|c|c|c|c|}
\hline & $n$ & $\begin{array}{l}\text { Crohn's } \\
\text { disease }\end{array}$ & $n$ & $\begin{array}{l}\text { Colon } \\
\text { carcinoma }\end{array}$ & & $\begin{array}{l}\text { Other } \\
\text { disorders }\end{array}$ \\
\hline $\begin{array}{l}\text { Yield } \\
\left(\times 10^{6} \text { cells } / g\right)\end{array}$ & 14 & $32 \cdot 9(4 \cdot 1)^{*}$ & 24 & $21 \cdot 0(3 \cdot 0)$ & 10 & $23 \cdot 7(3 \cdot 4)$ \\
\hline Viability (\%) & 11 & $84 \cdot 0(2 \cdot 1) \dagger \S$ & $\$ 23$ & $76 \cdot 1(1 \cdot 7)$ & 9 & $75 \cdot 1(2 \cdot 8)$ \\
\hline Macrophages (\%) & 14 & $7.9(1.0) \dagger$ & 20 & $12 \cdot 1(1 \cdot 3)$ & 5 & $11 \cdot 1(1 \cdot 7)$ \\
\hline Lymphocytes (\%) & 14 & $63 \cdot 0(3 \cdot 8)^{*} \ddagger$ & $\$ 20$ & $51 \cdot 3(3 \cdot 4)$ & 5 & $47 \cdot 3(6 \cdot 8)$ \\
\hline Plasma cells $(\%)$ & 9 & $4 \cdot 8(0 \cdot 8) \dagger$ & 10 & $12 \cdot 8(1 \cdot 8)$ & 5 & $6 \cdot 4(2 \cdot 5)$ \\
\hline Eosinophils (\%) & 9 & $5 \cdot 6(1 \cdot 2)$ & 12 & $7 \cdot 7(1 \cdot 5)$ & 5 & $14 \cdot 7(5 \cdot 5)$ \\
\hline
\end{tabular}

*Significant difference $\mathrm{p}<0.05$ Crohn's disease $v$ colon carcinoma; $(\dagger p<0.02)$; $\ddagger$ significant difference $p<0.05$ Crohn's disease $v$ other disorders $(\$ p<0 \cdot 02)$. Results expressed as mean $(\mathrm{SE})$.

Table 2 Percentage distribution of subpopulations of Tlymphocytes in the total lymphocyte population isolated from the lamina propria of resected intestine from patients with Crohn's disease or colon carcinoma as identified by membrane determinants

\begin{tabular}{lll}
\hline & $\begin{array}{l}\text { Crohn's disease } \\
(n=5)\end{array}$ & $\begin{array}{l}\text { Colon carcinoma } \\
(n=8)\end{array}$ \\
\hline $\mathrm{T}_{3}^{+}$pan T-cell & $86 \cdot 2(2 \cdot 9)$ & $75 \cdot 8(4 \cdot 3)$ \\
$\mathrm{T}_{4}^{+}$helper & $63 \cdot 2(1 \cdot 3)$ & $59 \cdot 1(2 \cdot 4)$ \\
$\mathrm{T}_{8}^{+}$suppressor & $24 \cdot 4(1 \cdot 7)$ & $23 \cdot 3(3 \cdot 4)$ \\
$\mathrm{T}_{4} / \mathrm{T}_{8}$ ratio & $2 \cdot 6(0 \cdot 2)$ & $3 \cdot 1(0 \cdot 6)$ \\
\hline
\end{tabular}

jugated rabbit antihuman $\operatorname{IgA}$, IgG, and IgM were added to the respective plates and again incubated at $37^{\circ} \mathrm{C}$ for 2.5 hours. After washing the enzyme reaction was evoked by adding the substrate Pnitrophenylphosphate and incubation at room temperature for approximately 45 minutes. The reaction was stopped by adding $\mathrm{NaOH}$ and the plates were read at $405 \mathrm{~nm}$ with a Titertek multiscan (Flow). By comparing the extinction of the samples with the extinction of the standard curves the amount of immunoglobulins was calculated. The amount of immunoglobulins produced by the cells was expressed as nanograms $/ 1 \times 10^{6}$ cells $/ \mathrm{ml}$.

\section{CELL IDENTIFICATION}

Cytospin preparations of intestinal mononuclear cells were fixed in methanol and stained with MayGrünwald Giemsa. The percentage of lymphocytes, monocytes/macrophages, granulocytes, plasma cells, and other cells was determined by counting 200-500 cells by light microscopy. Plasma cells were also identified by immunofluorescent staining of cytoplasmic immunoglobulins as described by Hijmans $e t$ al. ${ }^{15}$ In short, cells were fixed in $95 \%$ ethanol-5\% glacial acetic acid, incubated with fluorescein (FITC) conjugated goat antihuman IgA, IgG, and IgM, counterstained with rhodamine labelled bovine albumin and counted by phase-fluorescence microscopy. Cells in suspension were stained by nonspecific esterase staining for monocytes and macrophages, although intestinal epithelial cells are also esterase positive, or by incubation of the cells with FITC conjugated antihuman immunoglobulin, at $37^{\circ} \mathrm{C}$ and adequate washing for $\mathrm{B}$ cell staining. T cell subsets and monocytes/macrophages were identified by incubation with the monoclonal antibodies $\mathrm{OKT}_{3}$ (pan T-cell), $\mathrm{OKT}_{4}$ (T-helper), $\mathrm{OKT}_{8}$ (Tsuppressor), $\mathrm{OKM}_{1} \quad$ (monocyte/macrophage), (ORTHO) and FITC conjugated goat antimouse-Ig and analysed on the fluorescence activated cell sorter (FACS).

\section{STATISTICAL ANALYSIS}

Results are expressed as means (SE). Comparisons were made when appropriate by Student's $t$ test (similar standard deviations) or separate variance analysis (significantly different standard deviations) for the cell identification results (Tables 1,2, and 3).

The results of the immunoglobulin synthesis were analysed by the Wilcoxon's rank-sum test for the comparison of patients with controls, a paired

Table 3 Percentage distribution of the major subpopulations of intestinal cells in the mononuclear cell fraction (LPMC) after Ficoll/Hypaque density centrifugation and in the lymphocyte ( $L P L)$ and macrophage $(L P M)$ enriched fractions obtained after counterflow elutriation centrifugation of the total cell population. For technical details see Methods

\begin{tabular}{|c|c|c|c|c|}
\hline Fraction & Lymphocytes & Macrophages & Plasma cells & Eosinophils \\
\hline LPMCCrohn’s disease [12] & $69 \cdot 3(4 \cdot 0) \ddagger$ & $14 \cdot 8(2 \cdot 0)$ & $5 \cdot 7(1 \cdot 1)^{*}$ & $1 \cdot 6(0 \cdot 3)$ \\
\hline Colon carcinoma $[18]$ & $60 \cdot 8(3 \cdot 3)$ & $15 \cdot 1(1 \cdot 5)$ & $10 \cdot 5(1.9)$ & $2.6(0.5)$ \\
\hline Other disorders [5] & $48 \cdot 5(7 \cdot 8)$ & $16 \cdot 2(4 \cdot 0)$ & $7 \cdot 4(3 \cdot 8)$ & $3.9(1.4)$ \\
\hline LPL Crohn's disease [9] & $89 \cdot 0(2 \cdot 6)$ & $1.9(0.4)$ & $0 \cdot 3(0 \cdot 1)^{*}$ & $0.2(0 \cdot 2)^{*}$ \\
\hline Colon carcinoma $[17]$ & $89 \cdot 6(1.7)$ & $1.8(0.4)$ & $1.2(0.4)$ & $0.9(0 \cdot 2)$ \\
\hline LPM Crohn's disease [8] & $18 \cdot 9(1.5) \dagger$ & $31 \cdot 8(2 \cdot 6)$ & $9 \cdot 5(1.9)^{*}$ & $26 \cdot 3(4 \cdot 6)$ \\
\hline Colon carcinoma [17] & $11 \cdot 8(1 \cdot 4)$ & $34 \cdot 6(3 \cdot 3)$ & $16 \cdot 8(1 \cdot 9)$ & $19 \cdot 8(3 \cdot 4)$ \\
\hline
\end{tabular}

*Significant difference $\mathrm{p}<0.05$ Crohn’s disease $v$ colon carcinoma $(\dagger p<0.01)$; $\ddagger$ significant difference $p<0.05$ Crohn’s disease $v$ other disorders. Number of experiments is indicated by []. 
Table 4 Immunoglobulin $A, G$, and $M$ production (in $n g / 1 \times 10^{6} \mathrm{cells} / \mathrm{ml}$ ) by intestinal mononuclear cells (LPMC) obtained by Ficoll-Hypaque density gradient centrifugation from patients with Crohn's disease, colon carcinoma and other disorders. For technical details see Methods

\begin{tabular}{clcl}
\hline & $\begin{array}{l}\text { Crohn's } \\
\text { disease }\end{array}$ & $\begin{array}{l}\text { Colon } \\
\text { carcinoma }\end{array}$ & $\begin{array}{l}\text { Other } \\
\text { disorders }\end{array}$ \\
\hline IgA Spont & $1278(421)[11]^{*}$ & $4713(1503)[15]$ & $5574(2928)[6]$ \\
PWM & $724(252)[11] \ddagger$ & $1432(397)[15] \ddagger$ & $1803(1093)[6] \dagger$ \\
ConA+PWM & $462(178)[5] \S$ & $1063(466)[4]$ & nd \\
IgG Spont & $839(610)[11]$ & $436(135)[15]$ & $283(194)[6]$ \\
PWM & $567(374)[11]$ & $168(41)[15]$ & $245(175)[6]$ \\
ConA+PWM & $80(23)[5]$ & $84(20)[4]$ & nd \\
IgM Spont & $208(59)[11]$ & $250(64)[15]$ & $455(253)[6]$ \\
PWM & $228(97)[11]$ & $155(33)[15] \dagger$ & $300(175)[6]$ \\
ConA+PWM & $47(12)[5] \S$ & $75(23)[4] \S$ & nd \\
\hline
\end{tabular}

*Significance $\mathrm{p}<0 \cdot 05$, Crohn's disease $v$ colon carcinoma; †significance $\mathrm{p}<0.05, \mathrm{PWM} v$ spontaneous $(\neq \mathrm{p}<0.01)$; §significance $\mathrm{p}<0.05$, ConA + PWM $v$ PWM; nd = not done. Number of experiments is indicated by [ ].

analysis was used to evaluate the effect of stimulation with PWM and ConA (Table 4, Figs 1,2).

\section{Results}

\section{CELLS USED IN THE STUDY IN RELATION TO DISEASE}

The amount of cells isolated from Crohn's disease tissue was higher than from the control tissue (Table $1)$. There seems to be some differences in the subpopulations of isolated intestinal related to the disease state. There was a significant increased percentage of lymphocytes, without changes in the T-cell subsets, and a lower percentage of plasma cells and macrophages in Crohn's disease tissue compared with the control tissues (Tables 1,2). Density centrifugation resulted in the intestinal mononuclear cell fraction (LPMC) and subsequent counterflow elutriation centrifugation gave two major LPMC subpopulations - that is, fraction 0-1 with predominantly lymphocytes (LPL) and fraction 5 enriched for macrophages (LPM) (Table 3). The yield after Ficoll/ Hypaque remained higher $(\mathrm{p}<0.05)$ in Crohn's disease $\left(18.7(2.4) \times 10^{6}\right.$ cells/g) compared with the colon carcinoma group $(10.7(2.0))$ and the other disorders group $(10.7(2 \cdot 2))$ with a concurrent increase in the viability of the cells obtained (respectively $89.0 \%(1.6), 82.3 \%(2.9)$, and $83.2 \%$ $(2 \cdot 8)$. Only small differences in the fractions were observed between Crohn's disease and the control groups as shown in Table 3.

\section{IMMUNOGLOBULIN SYNTHESIS BY LAMINA} PROPRIA MONONUCLEAR CELLS

To ensure that the immunoglobulin synthesis in the

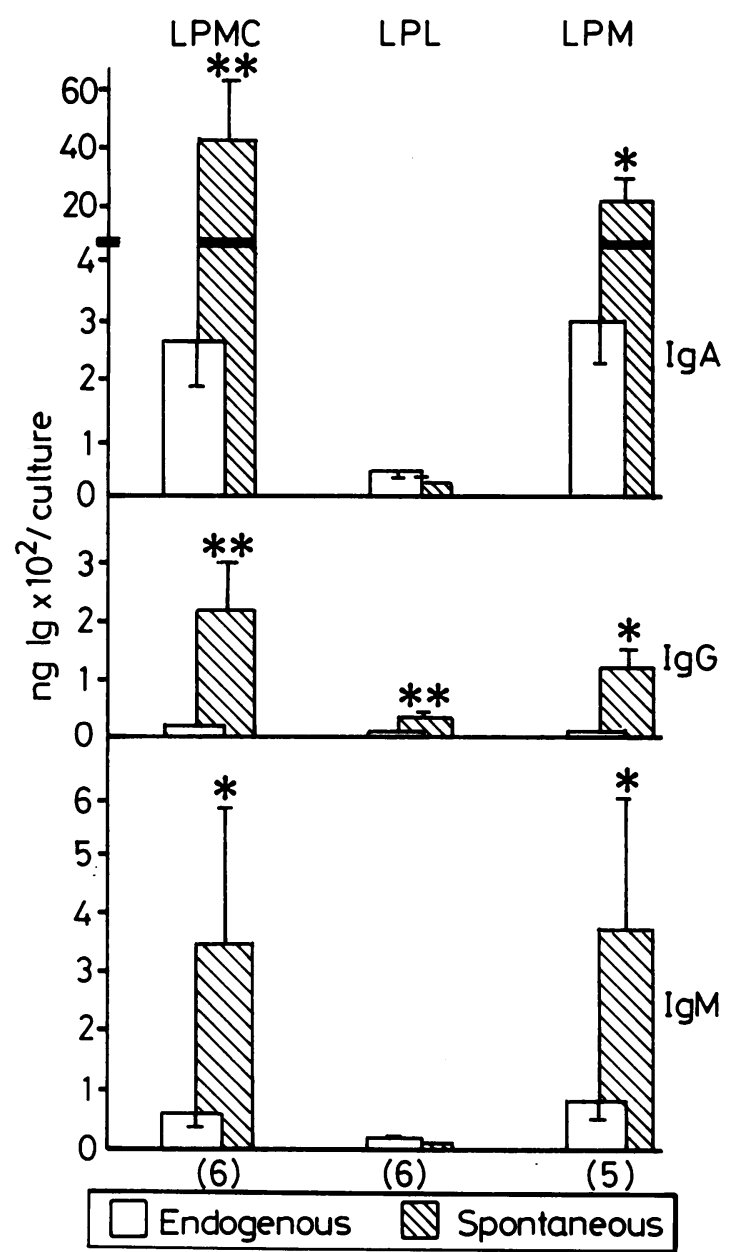

Fig. 1 Immunoglobulin $A, G$, and $M$ endogenously present and spontaneously produced by $1 \times 10^{6}$ lamina propria mononuclear cells $(L P M C)$, lymphocytes ( $L P L)$, and macrophages ( $L P M)$. The specimens were from three Crohn's disease patients and three (for LPM from two) controls, two colon carcinoma, and one diverticulitis. Note the shift in scale in the IgA. Figures in parentheses indicate the number of experiments.

*Significant difference $p<0.05$ between endogenous and spontaneous immunoglobulins, $\left({ }^{* *} p<0 \cdot 02\right)$.

three fractions studied were caused by de novo synthesis, the amount of immunoglobulins present in the cell fraction put in culture were compared with that spontaneously produced and secreted in the supernatants after one week culture (Fig. 1). The total mononuclear cells (LPMC) and the macrophage enriched fraction (LPM) showed a high de novo synthesis with a four to 20 -fold increase over the endogenous immunoglobulin. The lymphocyte enriched fraction (LPL), however, showed no 


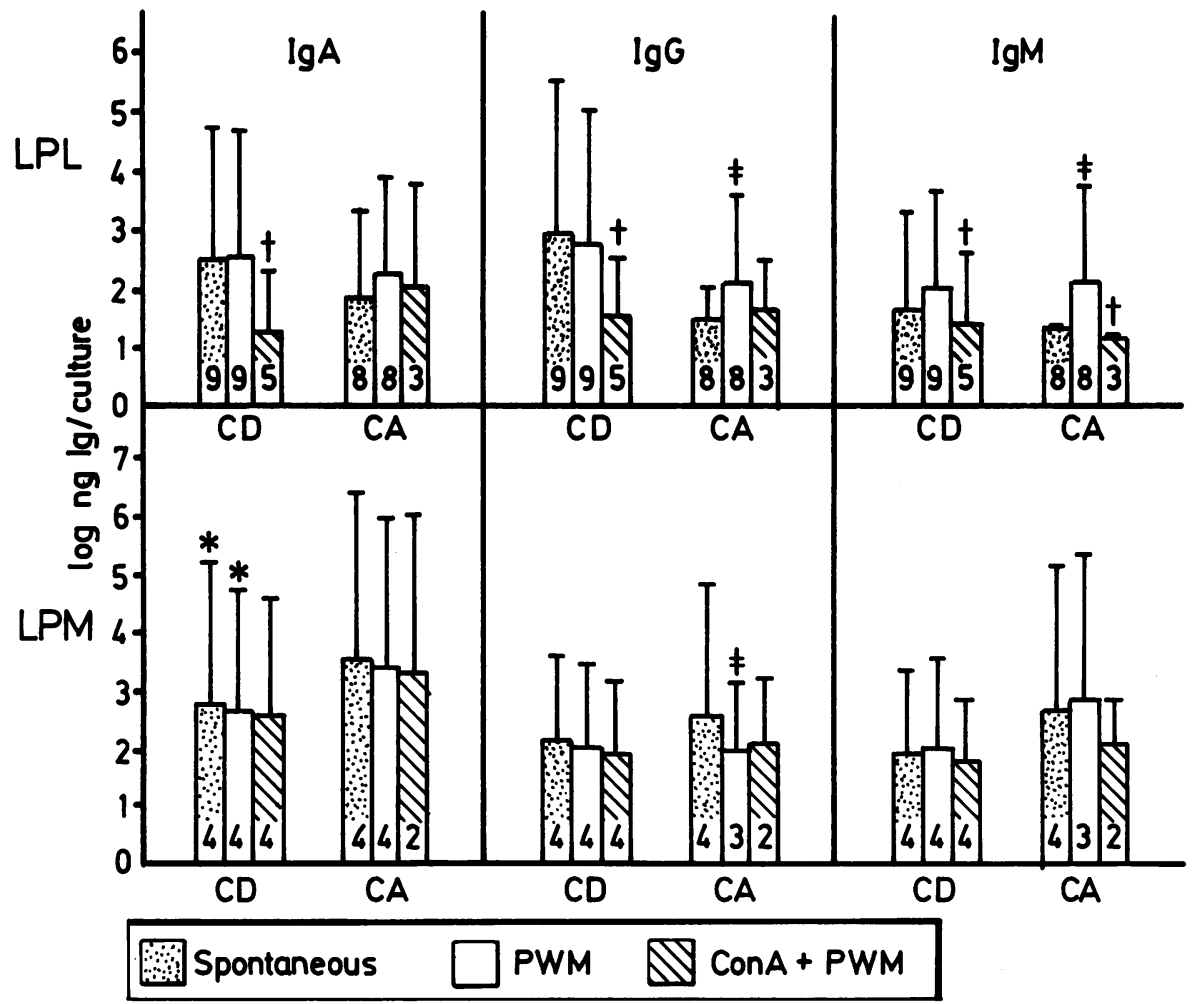

increase in the seven days spontaneous immunoglobulin synthesis over the immunoglobulins present in the cells at the start of the cultures as could be expected. In relation to the de novo immunoglobulin synthesis the results in the Crohn's disease group showed a similar pattern to that in colon carcinoma control group.

The spontaneous immunoglobulin production by the total intestinal mononuclear cells (LPMC) turned out to be predominantly (50-90\%) of the IgA class (Table 4). The spontaneous production of IgG and IgM was usually much lower and they were almost the same in quantity. In Crohn's disease, however, the spontaneous immunoglobulin synthesis was altered in the sense that there was a significant paucity in the IgA production, a normal IgM production and an increase in the IgG production compared with the control groups. No differences were observed in the immunoglobulin synthesis by cells from the small intestine compared with those from the large intestine in the patients with Crohn's disease and controls. Pokeweed mitogen stimulation of the LPMC both in patients with Crohn's disease and controls resulted in an inhibition of the immunoglobulin synthesis compared with the spontaneous production. This inhibition was most pronounced for $\operatorname{IgA}$ and IgG and was less or absent for IgM in the controls and Crohn's disease respectively. Although Crohn's disease still had reduced $\operatorname{IgA}$ and enhanced IgG synthesis no major differences in the immunoglobulin production after PWM incubation were observed between the groups studied. Simultaneous incubation with ConA augmented this PWM suppression in Crohn's disease patients and controls (Table 4).

The response of the LPMC fractions enriched by elutriation centrifugation differed considerably from that of the total cell population obtained after density gradient centrifugation. The lamina propria lymphocytes (LPL, fraction 0-1) from Crohn's disease 
patients produced spontaneously much more IgA (five fold) and IgG (30-fold), although not significantly, than those of the controls, whereas the production of IgM was almost equal (Fig. 2). Pokeweed mitogen incubation had no inhibitory effect on the immunoglobulin synthesis of the LPL but, on the contrary, stimulated the immunoglobulin synthesis in controls and resulted in some (IgM) or no (IgA) stimulation or a slight reduction (IgG) in Crohn's disease. The sensitivity of the LPL towards the inductive signals is illustrated moreover by the high suppression found upon simultaneous ConA incubation both for Crohn's disease and control patients (Fig. 2).

The macrophage enriched fraction (LPM, fraction 5) of Crohn's disease patients generally produced less immunoglobulins than that of control patients both spontaneously and after PWM incubation which, however, was only statistically significant for $\operatorname{IgA}$ $(p<0.05)$. It was also remarkable that again in this fraction PWM had an inhibitory, but not a stimulatory effect on the immunoglobulin synthesis. Simultaneous incubation of PWM and ConA did not enhance this suppression (Fig. 2).

\section{Discussion}

In the present study we investigated the in vitro immunoglobulin synthesis by intestinal mononuclear cells (LPMC) in Crohn's disease. The main findings of this study can be summarised as follows; (1) the total LPMC in Crohn's disease were found to produce spontaneously less IgA, normal IgM but more IgG compared with control LPMC, (2) analysis of the immunoglobulin synthesis by subpopulations of intestinal cells revealed that Crohn's disease patients had lymphocytes (LPL) with increased IgA and IgG synthesis associated with suppressed IgA, IgG, and IgM synthesis in the macrophage enriched cell population (LPM), (3) PWM failed to stimulate the immunoglobulin synthesis by all intestinal cell fractions in Crohn's disease in contrast with the controls where the LPL could be stimulated with PWM, (4) ConA reduced the immunoglobulin synthesis from LPMC and LPL in Crohn's disease and controls. The various results, as summarised above, point to a fundamental disordered regulation of the immunoglobulin synthesis at the intestinal level in Crohn's disease.

Until now only few studies have been carried out on the in vitro immunoglobulin synthesis by intestinal mononuclear cells in Crohn's disease and no studies on the effect of PWM and ConA on separated lymphocyte and macrophage subpopulations have been reported. Our results on the reduced spontaneous immunoglobulin synthesis correspond well with the results of previous reports of MacDermott $e t$ $a l^{6}$ and Elson $e t$ al. ${ }^{11}$ In relation to mitogenic stimulation of the immunoglobulin synthesis we found a constant decrease in the immunoglobulin synthesis, especially IgA and IgG, by LPMC upon stimulation with PWM. It is important to emphasise, however, that we used macroscopically uninvolved tissue from control and Crohn's disease patients. The decrease in the immunoglobulin synthesis by LPMC was also noticed by Drew et $a l^{10}$ who did a study on the regulation of the intestinal immunoglobulin synthesis by using normal tissue from colon carcinoma resections. They concluded that the intestinal cells were activated and committed to immunoglobulin secretion, even before being cultured, and were refractory to mitogenic stimuli. It is possible that the increase in the immunoglobulin synthesis to PWM by LPMC as shown by MacDermott et al ${ }^{6}$ and Elson et $a l^{11}$ was because of contamination of the tissue with responding peripheral blood lymphocytes at the site of active inflammation, especially as in the latter study the LPMC from grossly uninvolved Crohn's disease tissue responded less than those obtained from active lesions. In fact, several studies have already shown that blood lymphocytes of Crohn's disease patients and controls increase their immunoglobulin synthesis by PWM stimulation. ${ }^{6716}$

A further interesting finding in this study was that ConA incubation reduced the immunoglobulin synthesis considerably compared with the PWM incubation irrespective of the disease process. This means that some other suppressive activation can be achieved as well as the one already activated by PWM. This suppression seemed to be present in LPMC from Crohn's disease patients as well as from controls.

To elucidate the differences between Crohn's disease and controls and the non-response, or even inhibition of LPMC to PWM stimulation we studied the immunoglobulin synthesis by analysis of different subpopulations of LPMC. Elutriation centrifugation provided two major subpopulations - that is, lymphocytes (LPL) and macrophages (LPM). The LPL from Crohn's disease patients produced more $\operatorname{IgA}$ and IgG than those of controls and were found to be insensitive to PWM stimulation in contrast with LPL from controls. Control LPL thus behaved more like peripheral blood lymphocytes in the sense that they increased their immunoglobulin synthesis on PWM incubation which could be inhibited by simultaneous ConA stimulation. Surprisingly, LPL from Crohn's disease patients also showed this ConA inhibition similar to those of controls. This observation points to highly activated immunoglobulin production by LPL in Crohn's disease which cannot be further stimulated but, on the contrary, can be 
suppressed. In the macrophage enriched fraction the results showed a process just the opposite to that seen with the LPL. The spontaneous IgA, IgG, and IgM synthesis of LPM from Crohn's disease patients was considerably reduced compared with LPM from controls. Pokeweed mitogen was found to reduce the immunoglobulin synthesis and this reduction could not be enhanced by ConA incubation except for IgM. These results might indicate an activated macrophage population in Crohn's disease with a strong inhibiting activity on the immunoglobulin synthesis. The presence of an activated mononuclear phagocyte population in Crohn's disease was already found in relation with other immune response functions, such as phagocytosis, intracellular killing, and plasminogen activator activity (17-19).

The differences we have shown in the immunoglobulin synthesis of intestinal cells between Crohn's disease and controls cannot be attributed to variations in the cell populations used. The relative contribution T-lymphocytes, plasma cells and macrophages could not account for the differences found in the immunoglobulin synthesis between both groups. This observation is in accord with other studies where no severely altered cell populations in Crohn's disease were found. ${ }^{120}$

The relation between our observations of reduced IgA, normal IgM and increased IgG synthesis by LPMC in Crohn's disease and the reports on plasma cell counts of histological sections of the intestine seems to be unclear. Several studies indicated an increased number of $\operatorname{IgA}$, IgG, and IgM containing plasma cells in Crohn's disease compared with controls. ${ }^{22} 22$ When the absolute number of plasma cells would be converted to relative contributions of each class of immunoglobulin, however, most studies would show a decrease in percentage of IgA plasma cells at the expense of an increase in percentage of IgG and IgM plasma cells. These results would then agree with our observations on the culture of a fixed number of $\left(1 \times 10^{6}\right)$ intestinal cells. With regard to the class of immunoglobulin produced it still holds true that $\operatorname{IgA}$ is produced in higher absolute quantities than IgG and IgM, as is known for all mucosal tissue. In a study determining the immunoglobulin secretion by normal intestinal mucosal tissue Danis et $a l^{23}$ confirmed this predominant IgA secretion. They also observed increased $\mathrm{IgG}$ and reduced $\operatorname{IgA}$ secretion by intestinal tissue of Crohn's disease patients corresponding with our observations obtained with isolated intestinal cells.

In conclusion, the present observations provide evidence for a disturbed regulation of the immunoglobulin synthesis by intestinal mononuclear cells in Crohn's disease. The indications for activated lymphocytes and suppressive macrophages contri- buting in their own way to the local immunoglobulin synthesis necessitates further studies in order to understand the contribution of the immune system in the pathogenesis of Crohn's disease. At present, however, it is unclear whether the activated cells of the local immunoglobulin synthesis are the consequence of the inflammation or are involved in the initiation of the disease.

The authors thank Petra Lems-van Kan, Marij Mieremet-Ooms and Annie van der Zon for their skilful technical assistance and Karlien Kruijer for typing the manuscript.

\section{References}

1 Brandtzaeg P, Valnes K, Scott H, Rognum TO, Bjerke $\mathrm{K}$, Baklien $\mathrm{K}$. The human gastrointestinal secretory immune system in health and disease. Scand J Gastroenterol 1985; 20: suppl 114: 17-38.

2 Jewell DP, Patel C. Immunology of inflammatory bowel disease. Scand J Gastroenterol 1985; 20: suppl 114: 119-26.

3 Peña AS. Crohn's Disease. In: Triger DR, ed. Clinical immunology of the liver and gastrointestinal tract. Bristol: Wright, 1986: 100-12.

4 Sieber G, Herrmann F, Zeitz M, Teichmann H, Rühl H. Abnormalities of B-cell activation and immunoregulation in patients with Crohn's disease. Gut 1984; 25: 1255-61.

5 Danis VA, Heatley RV. Pokeweed mitogen stimulated immunoglobulin production by peripheral blood lymphocytes in vitro: evidence for disordered immunoregulation in patients with ulcerative colitis and Crohn's disease. Clin Exp Immunol 1983; 54: 739-46.

6 MacDermott RP, Nash GS, Bertovich MJ, Seiden MV, Bragdon MJ, Beale MG. Alterations of IgM, IgG, and IgA synthesis and secretion by peripheral blood and intestinal mononuclear cells from patients with ulcerative colitis and Crohn's Disease. Gastroenterology 1981; 81: 844-52.

7 Verspaget HW, Peña AS, Weterman IT, Lamers CBHW. Differences in the immunoglobulin synthesis by peripheral blood lymphocytes in Crohn's disease and ulcerative colitis. Digestion 1988 (In press).

8 Elson CO, Graeff AS, James SP, Strober W. Covert suppressor T-cells in Crohn's disease. Gastroenterology 1981; 80: 1513-21.

9 Bull DM, Bookman MA. Isolation and functional characterization of human intestinal mucosal lymphoid cells. J Clin Invest 1977; 59: 966-74.

10 Drew PA, La Brooy JT, Shearman DJC. In vitro immunoglobulin synthesis by human intestinal lamina propria lymphocytes. Gut $1984 ; 25$ : 649-55.

11 Elson CO, Machelski E, Weiserbs DB. T cell-B cell regulation in the intestinal lamina propria in Crohn's Disease. Gastroenterology 1985; 89: 321-7.

12 James SP, Fiocchi C, Graeff AS, Strober W. Immunoregulatory function of lamina propria T cells in Crohn's Disease. Gastroenterology 1985; 88: 1143-50. 
13 Beeken W, Mieremet-Ooms M, Ginsel LA, Leijh PCJ, Verspaget HW. Enrichment of macrophages in cell suspensions of human intestinal mucosa by elutriation centrifugation. J Immunol Meth 1984; 73: 189-201.

14 Lems-van Kan P, Verspaget HW, Peña AS. ELISA assay for quantitative measurement of human immunoglobulins IgA, IgG, and IgM in nanograms. $J$ Immunol Meth 1983; 57: 51-7.

15 Hijmans W, Schuit HRE, Klein F. An immunofluorescence procedure for the detection of intracellular immunoglobulins. Clin Exp Immunol 1969; 4: 457-72.

16 Holdstock G, Ershler WB, Krawitt EL. Defective lymphocyte $\operatorname{IgA}$ production in inflammatory bowel disease. Clin Immunol Immunopathol 1982; 24: 47-54.

17 Doe WF, Dorsman B. Chronic inflammatory bowel disease - increased plasminogen activator secretion by mononuclear phagocytes. Clin Exp Immunol 1982; 48: 256-60.

18 Mee AS, Szawatakowski M, Jewell DP. Monocytes in inflammatory bowel disease: phagocytosis and intracellular killing. J Clin Pathol 1980; 33: 921-5.
19 Beeken WL, Andre-Ukena SST, Gundel RM. Comparative studies of mononuclear phagocyte function in patients with Crohn's disease and colon neoplasms. Gut 1983; 24: 1034-40.

20 Selby WS, Janossy G, Bofill M, Jewell DP. Intestinal lymphocyte subpopulations in inflammatory bowel disease: an analysis by immunohistological and cell isolation techniques. Gut 1984; 25 : 32-40.

21 Baklien K, Brandtzaeg P. Comparative mapping of the local immunoglobulin-containing cells in ulcerative colitis and Crohn's disease of the colon. Clin Exp Immunol 1975; 22: 197-209.

22 Rosekrans PCM, Meijer CJLM, Lindeman J. Immunoglobulin containing cells in colonic and rectal mucosa in Crohn's Disease. In: Peña AS, Weterman IT, Booth CC, Strober W, eds. Recent advances in Crohn's disease. The Hague: Martinus Nijhoff, 1981: 94-9.

23 Danis VA, Harries AD, Heatley RV. In vitro immunoglobulin secretion by normal human gastrointestinal mucosal tissues, and alterations in patients with inflammatory bowel disease. Clin Exp Immunol 1984; 56: 159-66. 